\title{
Superparamagnetic iron oxide-enhanced magnetic resonance for imaging cardiac inflammation. A minireview
}

\author{
Helena Podrouzkovaa,c, Vera Feitova ${ }^{\mathrm{b}, \mathrm{c}}$, Roman Panovsky ${ }^{\mathrm{a}, \mathrm{c}}$, Jaroslav Meluzinn ${ }^{\mathrm{a}, \mathrm{c}}$, Marek Orban ${ }^{\mathrm{c}}$
}

\begin{abstract}
Background. Advances in nanotechnology have lead to the development of a novel contrast media for Magnetic Resonance Imaging (MRI) - the superparamagnetic iron oxide nanoparticle (SPIO). SPIO nanoparticles are used to image inflammation on the cellular level in various settings.

This review covers the physicochemical characteristics of SPIO particles as well as relevant animal and clinical studies and discusses the potential of SPIO particles to image cardiac inflammation including cardiac graft rejection.

Methods. We searched the scientific biomedical databases Medline/PubMed, BioMedCentral, Google Scholar, Ovid and, ProQuest from to 2000 to 2013 for publications relevant to the topic.

Conclusions. SPIO nanoparticles due to their unique properties could become a useful tool in imaging cardiac inflammation. However, the task is to find a suitable particle size and coating with corresponding pharmacokinetics, establish the right dose and MRI scan timing for individual applications.
\end{abstract}

Key words: magnetic resonance imaging, inflammation, superparamagnetic iron oxide

Received: October 11, 2013; Accepted with revision: May 29, 2014; Available online: June 19, 2014 http://dx.doi.org/10.5507/bp.2014.030

\author{
aDepartment of Cardiovascular Diseases, ICRC, St. Anne's University Hospital in Brno, Czech Republic \\ ${ }^{b}$ Department of Imaging Methods, ICRC, St. Anne's University Hospital in Brno \\ 'ICRC, St. Anne's University Hospital in Brno \\ Corresponding author: Marek Orban, e-mail:maor@post.cz
}

\section{CHARACTERISTICS OF SPIO}

Advances in nanotechnologies in the last decades have enabled vast progress in molecular and cellular imaging. It allows the non-invasive visualization of the cells and even molecules inside living organisms. One of the substances capable of imaging cells in Magnetic Resonance Imaging (MRI) is the superparamagnetic iron oxide nanoparticle (SPIO). SPIO particles for intravenous use consist of an iron oxide (maghemite or magnetite; $\gamma$-Fe2O3 or Fe3O4) core coated with dextran or carboxydextran. The coating isolates iron core from plasma components thus prolonging plasma circulation time. It also prevents particles from aggregation and makes them biocompatible, soluble and stable ${ }^{1}$.

\section{Mechanism of action}

The main principle behind SPIO nanoparticles is their large magnetic moment in the presence of an external magnetic field, but no magnetic moment when the field is zero ${ }^{2}$. This is referred to as superparamagnetism.

In the MRI, the presence of SPIO particles leads to shortening of the T2/T2* relaxation time. In other words, the SPIO particles are visible in MRI as hypointensities in the T2 weighted image. Under certain circumstances, the SPIO particles can also have a T1 relaxation effect.

There are a variety of core sizes and types of coating corresponding to different pharmacokinetics, blood half- life, biodistribution and magnetic properties of each particle ${ }^{3}$. The nanoparticle coating allows the attachment of various ligands ${ }^{4}$.

After intravenous administration, the SPIO particles are eliminated from blood by being phagocytosed by circulating immune cells, mostly macrophages. In case of greater permeability of the vessel walls, such as occurs in inflammation, the SPIO particles leak into the interstitium and become phagocytosed by tissue macrophages. Thus, macrophages become labeled and detectable in MRI in vivo. The iron core is released from the coating inside of a macrophage. Iron then either enters the intracellular storage iron pool as ferritin or is transferred to plasma as transferrin. The latter is transported to erythroid precursor cells in bone marrow to be incorporated into haemoglobin ${ }^{5}$.

The viability and function of human mononuclear peripheral blood cells labelled with SPIO particles remains unaffected. After in vitro labeling, these cells were injected into the venous system and were tracked to the site of inflammation - a tuberculin skin test in healthy volunteers ${ }^{6}$.

\section{Types of SPIO}

SPIO nanoparticles are classified by size as very small (4-8 nm), ultrasmall (10-40 nm), small (60-200 nm) and large $(300 \mathrm{~nm}-3.5 \mu \mathrm{m})$. See Table 1 .

The size of the particle determines its biodistribution and plasma circulation time ${ }^{1}$. Generally, the larger particles, the faster the uptake into the reticuloendothelial system cells, and the better the contrast on MRI. Smaller 
Table 1. Overview of clinically tested types of SPIO.

\begin{tabular}{|c|c|c|}
\hline International non-proprietary name & Particle size & Indications \\
\hline Ferumoxid & $120-180 \mathrm{~nm}$ & liver imaging, cell labeling \\
\hline Ferumoxtran & $15-30 \mathrm{~nm}$ & $\begin{array}{l}\text { metastatic lymph node and macrophage imaging, blood } \\
\text { pool agents, cell labeling }\end{array}$ \\
\hline Ferumoxytol & $30 \mathrm{~nm}$ & $\begin{array}{l}\text { iron deficiency anemia treatment in patients with } \\
\text { chronic kidney disease, macrophage imaging, blood } \\
\text { pool agent, cell labeling }\end{array}$ \\
\hline Ferumoxsil & $300 \mathrm{~nm}$ & orally administered for gastrointestinal system imaging \\
\hline Ferucarbotran & $21 \mathrm{~nm}$ & blood pool agent, cell labeling, liver imaging \\
\hline
\end{tabular}

Modified from ${ }^{1,2,6}$

particles have a longer blood half-life and larger fraction may end up in the lymphatic system. The smaller particle, the deeper it can travel into a tissue. There is a variety of types of coating corresponding to different pharmacokinetics ${ }^{3}$. Nanoparticle coating allows attachment of various ligands, such as macrophage receptors, monoclonal antibodies or cell adhesion molecules ${ }^{4,7}$.

\section{Comparison to gadolinium}

SPIO particles as MRI contrast agents, offer several advantages over gadolinium contrast agents. They are safe to use in patients with or at risk of nephrogenic systemic fibrosis. Compared to gadolinium, the superparamagnetic contrast media do not leak into interstitium, have a long blood half-life and higher relaxivity. This together with better safety profile and accumulation in macrophages, could make SPIO particles compete with gadolinium contrast agents in the future.

\section{Vascular contrast media}

The long blood circulating half-life and no leak into the interstitium makes SPIO particles a perfect vascular contrast medium. It has been shown in human studies, that SPIO enhanced MRI was suitable for imaging of large vascular structures such as cardiac chambers, aorta and pulmonary arteries ${ }^{8}$. It was better than non-enhanced MRI in depicting deep vein thrombosis ${ }^{9}$ and hemodialysis fistulas ${ }^{10}$. SPIO-enhanced MRI was tested for imaging myocardial perfusion ${ }^{11}$ and for MRI coronary angiography, where SPIO particles were moderately accurate in the detection of significant coronary artery stenosis ${ }^{12}$.

\section{Imaging of inflammation}

SPIO particles showed not only the ability to image inflammatory processes in vivo ${ }^{13,14}$, but also demonstrated the potential to monitor the effect of anti-inflammatory drugs in a number of studies, both animal ${ }^{15,16}$ and hu$\operatorname{man}^{17}$. There are two ways how SPIO particles display the inflammation. One actually visualizes increased vessel wall permeability. SPIO particles are strictly intravascular pool agents, meaning they only leak into interstitium in case of higher permeability of vessel wall, as observed in inflammation. Inflammation is then seen as a perivascular leak of SPIO. This effect is achieved early after intravenous administration of SPIO. The latter comes when the particles are phagocytosed by the macrophages. It happens both in the blood stream and in the area of inflammation. The SPIO labeled macrophages are visible on MRI T2 weighted image as dark speckles or hypointensities in the tissue. These two effects overlap in time, with the former prevailing hours after drug administration, the later approximately one to two days after the administration. In a study in mice with experimental stroke, it has been shown that most of the SPIO enhancement 24-hours post ischemic brain injury was caused by non-specific mechanisms such as brain-blood barrier leakage, rather than peripheral phagocyte infiltration ${ }^{15,18}$. After $48 \mathrm{~h}$ post ischemic brain injury, most iron related signal changes on MRI were indisputably associated with macrophages, as detected on histology ${ }^{19}$.

Atherosclerosis is now understood as a multi-factorial chronic inflammatory disease, characterized by intense immunological activity with macrophages and T-lymphocytes being the major players. The high macrophage content in the atherosclerosis plaque in SPIOenhanced MRI is considered a sign of a plaque vulnerable to rupture due to ongoing inflammation ${ }^{20}$. Similarly, in cerebral aneurysms, the uptake of SPIO particles in MRI is a sign of instability with a higher probability of rupture ${ }^{21}$. SPIO enhanced MRI in human carotid atheroma identified macrophages in vivo, which was validated with histology in patients scheduled for carotid endarterectomy ${ }^{22}$. The SPIO enhanced MRI was also used for testing the effect of aggressive lipid-lowering therapy in both animal ${ }^{16}$ and human carotid plaque ${ }^{17}$.

Myocardial infarction is associated with inflammation, as an influx of macrophages can be seen in post mortem histology. The effect of anti-inflammatory drugs after acute myocardial infarction has been tested with the prospect of better myocardial repair and regeneration. In recently published studies, SPIO particles were used to visualize the inflammation accompanying acute myocardial infarction in humans ${ }^{23-25}$.

Acute cellular graft rejection of the heart is characterized by immune cell infiltration, edema and myocyte damage, which results in impaired mechanical left ven- 
tricle function. Most non-invasive approaches to detect rejection, display only the result - the disturbance in ventricle mechanics. In contrast, the SPIO particles have a potential to display the primary process and thus detect graft rejection in very early stages.

In animal studies, SPIO particles showed the ability to detect rejection in renal, lung and heart transplants in rats $^{26}$. Macrophages labeled with SPIO particles induced a significant decrease in MR signal intensity in the allograft, and the degree of signal attenuation had an excellent correlation with the pathological rejection grade ${ }^{27,28}$. Another study in rats showed acute cardiac transplant rejection using SPIO blood pool contrast agent. MRI was performed 43 min after SPIO infusion and featured increased vessel permeability for iron oxide in rat hearts undergoing rejection. The degree of rejection confirmed by histology correlated with increase in endothelial permeability for iron oxide particles ${ }^{29}$.

To the best of our knowledge, there has been no human study applying SPIO enhanced MRI to detect heart transplant rejection as human applications have many pitfalls. Moderate and severe graft rejection demands immediate treatment which results in immediate immune response. From this point of view, a time period of 24 to $48 \mathrm{~h}$ from administering contrast agent to MRI may seem too long and perhaps a blood pool contrast agent would be more suitable in clinical settings.

A human study using SPIO enhanced MRI in the field of transplantology was the one by Hauger et al. and involved the kidneys. This team published a study where SPIO-enhanced MRI was applied for imaging macrophage infiltration in kidneys in patients scheduled for kidney biopsy. Two patients with transplant kidneys were included. In these two patients, MRI revealed a clear visible signal loss in all renal compartments, more pronounced in the medulla. Histological examination revealed numerous macrophages, resulting in diagnosis of acute kidney rejection ${ }^{14}$.

In experimental autoimmune myocarditis in rats, the iron oxide superparamagnetic and fluorescent nanoparticles provided better image contrast and detectability of focal myocardial inflammation compared to conventional MRI (ref. ${ }^{30}$ ). To our knowledge, there has been no human study published using SPIO enhanced MRI in myocarditis or sarcoidosis yet.

\section{CONCLUSION}

SPIO-enhanced MRI has shown clinical potential in various medical fields and several advantages over gadolinium, such as better safety profile and macrophage accumulation. SPIO nanoparticles have proven ability to feature myocardial inflammation in various animal studies and lately also in patients after myocardial infarction, yet further clinical use of SPIO nanoparticles in imaging cardiac inflammation remains to be a challenge.

\section{ABBREVIATIONS}

SPIO, Superparamagnetic iron oxide; MRI, Magnetic resonance imaging.

\section{ACKNOWLEDGEMENT}

This study was supported in part by the European Regional Development Fund - Project FNUSA-ICRC (No. CZ.1.05/1.1.00/02.0123).

Author contributions: HP: literature search and manuscript writing; VF, MO, RP, JM: manuscript revision and final approval.

Conflict of interest statement: None declared.

\section{REFERENCES}

1. Kumar C. Magnetic Nanomaterials as MRI contrast agents. In: Kumar C, editor. Magnetic Nanomaterials. 2009. p. 119-135.

2. Bjørnerud A, Johansson L. The utility of superparamagnetic contrast agents in MRI: theoretical consideration and applications in the cardiovascular system. NMR Biomed 2004;17:465-77.

3. Di Marco M, Sadun C, Port M, Guilbert I, Couvreur P, Dubernet C. Physicochemical characterization of ultrasmall superparamagnetic iron oxide particles (USPIO) for biomedical application as MRI contrast agents. Int J Nanomedicine 2007;2:609-22.

4. Thorek DLJ, Chen AK, Czupryna J, Tsourkas A. Superparamagnetic iron oxide nanoparticle probes for molecular imaging. Ann Biomed Eng 2006;34:23-38.

5. EMEA [Internet]. Official website of European Medicines Agency. [cited 2013 Apr 4];Available from: www.emwww.ema.europa.eu

6. Richards JMJ, Shaw C a, Lang NN, Williams MC, Semple SIK, MacGillivray TJ, Gray C, Crawford JH, Alam SR, Atkinson APM, Forrest EK, Bienek C, Mills NL, Burdess A, Dhaliwal K, Simpson a J, Wallace W a, Hill AT, Roddie PH, McKillop G, Connolly T a, Feuerstein GZ, Barclay GR, Turner ML, Newby DE. In vivo mononuclear cell tracking using superparamagnetic particles of iron oxide: feasibility and safety in humans. Circ Cardiovasc Imaging 2012;5:509-17.

7. Sosnovik DE. Magnetic nanoparticles for MR imaging: agents, techniques and cardiovascular applications. Basic Res Cardiol 2008;103:122-30.

8. Prince MR, Zhang HL, Chabra SG, Jacobs P, Wang Y. A pilot investigation of new superparamagnetic iron oxide (ferumoxytol) as a contrast agent for cardiovascular MRI. J Xray Sci Technol 2003;11:231-40.

9. Li W, Salanitri J, Tutton S, Dunkle EE, Schneider JR, Pierchala LN, Jacobs PM, Edelman RR. Lower Extremity Deep Venous Thrombosis: Evaluation with Ferumoxytol-enhanced MR Imaging and Dual-Contrast Mechanism-Preliminary Experience. Radiology 2007;242:873-81.

10. Sigovan M, Gasper W, Alley HF, Owens CD, Saloner D. USPIOenhanced MR angiography of arteriovenous fistulas in patients with renal failure. Radiology 2012;265:584-90.

11. Reimer P, Bremer C, Allkemper T, Engelhardt M, Mahler M, Ebert W, Tombach B. Radiology Myocardial Perfusion and MR Angiography of Chest with SH U 555 C : Results of Placebo-controlled Clinical Phase I Study. Radiology 2004;231:474-81.

12. Wagner M, Wagner S, Schnorr J, Schellenberger E, Kivelitz D, Krug L, Dewey M, Laule M, Hamm B, Taupitz M. Coronary MR angiography using citrate-coated very small superparamagnetic iron oxide particles as blood-pool contrast agent: initial experience in humans. Journal of magnetic resonance imaging : JMRI 2011;34:816-23.

13. Saleh A, Schroeter M, Jonkmanns C, Hartung H-P, Mödder U, Jander $\mathrm{S}$. In vivo MRI of brain inflammation in human ischaemic stroke. Brain: a journal of neurology. 2004;127:1670-7.

14. Hauger $O$, Grenier N, Deminère $C$, Lasseur $C$, Delmas $Y$, Merville $P$, Combe $\mathrm{C}$. USPIO-enhanced MR imaging of macrophage infiltration in native and transplanted kidneys: initial results in humans. Eur Radiol 2007;17:2898-907. 
15. Marinescu M, Chauveau F, Durand A, Riou A, Cho T-H, Dencausse A, Ballet S, Nighoghossian N, Berthezène $Y$, Wiart M. Monitoring therapeutic effects in experimental stroke by serial USPIO-enhanced MRI. Eur Radiol 2013;23:37-47.

16. Morishige K, Kacher DF, Libby P, Josephson L, Ganz P, Weissleder R, Aikawa $M$. High-resolution magnetic resonance imaging enhanced with superparamagnetic nanoparticles measures macrophage burden in atherosclerosis. Circulation 2010;122:1707-15.

17. Tang TY, Howarth SPS, Miller SR, Graves MJ, Patterson AJ, U-KingIm J-M, Li ZY, Walsh SR, Brown AP, Kirkpatrick PJ, Warburton E a, Hayes PD, Varty K, Boyle JR, Gaunt ME, Zalewski A, Gillard JH. The ATHEROMA (Atorvastatin Therapy: Effects on Reduction of Macrophage Activity) Study. Evaluation using ultrasmall superparamagnetic iron oxide-enhanced magnetic resonance imaging in carotid disease. Journal of the American College of Cardiology 2009;53:2039-50.

18. Desestret V, Brisset J-C, Moucharrafie S, Devillard E, Nataf S, Honnorat J, Nighoghossian N, Berthezène Y, Wiart M. Early-stage investigations of ultrasmall superparamagnetic iron oxide-induced signal change after permanent middle cerebral artery occlusion in mice. Stroke 2009;40:1834-41.

19. Wiart M, Davoust N, Pialat J-B, Desestret V, Moucharrafie S, Moucharaffie S, Cho T-H, Mutin M, Langlois J-B, Beuf O, Honnorat $J$, Nighoghossian N, Berthezène Y. MRI monitoring of neuroinflammation in mouse focal ischemia. Stroke 2007;38:131-7.

20. Korosoglou G, Weiss RG, Kedziorek DA, Walczak P, Gilson WD, Schär M, Sosnovik DE, Kraitchman DL, Boston RC, Bulte JWM, Weissleder R, Stuber M. Noninvasive detection of macrophage-rich atherosclerotic plaque in hyperlipidemic rabbits using "positive contrast" magnetic resonance imaging. J Am Coll Cardiol 2008;52:483-91.

21. Hasan D, Chalouhi N, Jabbour P, Dumont AS, Kung DK, Magnotta $V$ a, Young WL, Hashimoto T, Winn HR, Heistad D. Early change in ferumoxytol-enhanced magnetic resonance imaging signal suggests unstable human cerebral aneurysm: a pilot study. Stroke 2012;43:3258-65

22. Trivedi R a, U-King-Im J-M, Graves MJ, Cross JJ, Horsley J, Goddard MJ, Skepper JN, Quartey G, Warburton E, Joubert I, Wang L, Kirkpatrick PJ, Brown J, Gillard JH. In vivo detection of macrophages in hu- man carotid atheroma: temporal dependence of ultrasmall superparamagnetic particles of iron oxide-enhanced MRI. Stroke 2004;35:1631-5.

23. Yilmaz A, Rösch S, Yildiz H, Klumpp S, Sechtem U. First multiparametric cardiovascular magnetic resonance study using ultrasmall superparamagnetic iron oxide nanoparticles in a patient with acute myocardial infarction: new vistas for the clinical application of ultrasmall superparamagnetic iron oxide. Circulation 2012;126:1932-4.

24. Yilmaz A, Rösch S, Klingel K, Kandolf R, Helluy X, Hiller K-H, Jakob PM, Sechtem U. Magnetic resonance imaging (MRI) of inflamed myocardium using iron oxide nanoparticles in patients with acute myocardial infarction - preliminary results. Int J Cardiol 2013;163:175-82.

25. Alam SR, Shah AS V, Richards J, Lang NN, Barnes G, Joshi N, MacGillivray T, McKillop G, Mirsadraee S, Payne J, Fox KAA, Henriksen P, Newby DE, Semple SIK. Ultrasmall superparamagnetic particles of iron oxide in patients with acute myocardial infarction: early clinical experience. Circ Cardiovasc Imaging 2012;5:559-65.

26. Kanno S, Wu Y-JL, Lee PC, Dodd SJ, Williams M, Griffith BP, Ho C. Macrophage Accumulation Associated With Rat Cardiac Allograft Rejection Detected by Magnetic Resonance Imaging With Ultrasmall Superparamagnetic Iron Oxide Particles. Circulation 2001;104:934-8.

27. Wu YL, Ye Q, Sato K, Foley LM, Hitchens TK, Ho C. Noninvasive evaluation of cardiac allograft rejection by cellular and functional cardiac magnetic resonance. JACC. Cardiovascular imaging. 2009;2:731-41.

28. Christen $T$, Nahrendorf M, Wildgruber M, Swirski FK, Aikawa $E$, Waterman P, Shimizu K, Weissleder R, Libby P. Molecular imaging of innate immune cell function in transplant rejection. Circulation 2009;119:1925-32.

29. Johansson L, Johnsson C, Penno E. Acute Cardiac Transplant Rejection: Detection and Grading with MR Imaging with a Blood Pool Contrast Agent - Experimental Study in the Rat 1. Radiology 2002;225:97-103.

30. Moon H, Park HE, Kang J, Lee H, Cheong C, Lim YT, Ihm S-H, Seung K-B, Jaffer F a, Narula J, Chang K, Hong KS. Noninvasive assessment of myocardial inflammation by cardiovascular magnetic resonance in a rat model of experimental autoimmune myocarditis. Circulation 2012;125:2603-12. 